\title{
Thermal Management Roadmap for Energy Efficient Next Generation Telecommunications Equipment
}

\author{
Lian-Tuu Yeh, Ph D \& PE \\ ASME Fellow \\ Thermal Consultant \\ Dallas, Texas \\ Email :jjyeh2@aol.com
}

Keywords: Electronic Cooling, thermal management, telecommunication systems, liquid cooling, energy efficiency, alternative energy

\begin{abstract}
The network traffic in telecommunication industry has grown very rapidly every year since its inception. As projected, the network traffic demand will reach tens or hundreds of $\mathrm{Tb} / \mathrm{s}$ in a couple of years. With the extrapolation from current equipment, future nodes would consume and dissipate up to 100's of kilowatts of power. In response to the projected growth, new design and architecture are needed in order to face the power-density challenges in the next generation telecommunication networks. There are two aspects of these issues. One is the network architecture and another is telecommunication equipment design. The thermal management of latter case is the focus of this paper.
\end{abstract}

\section{Introduction}

The network traffic in telecommunication industry has grown very rapidly every year since its inception. As projected, the network traffic demand will reach tens or hundreds of $\mathrm{Tb} / \mathrm{s}$ in a couple of years. In response to the projected growth, new design and architecture are needed in order to face the power-density challenges in the next generation telecommunication networks. There are two aspects of these issues (1). One is the network architecture and another is telecommunication equipment design.

The main goal of the architecture is to minimize the total power per network throughput. To achieve this goal, one can employ the so called all-optical network (AON) which keeps the transfer of bits in the optical domain with a "less power hungry" networks. The second issue deals with the telecommunication equipment design. The main challenge of high-density and high speed equipment is the thermal management which must include a balanced combination of materials, technologies and cost.

With the equipment power increased at the fast pace plus a significant increase in energy consumption at the date centers, the cost of powering and cooling of the equipment and the data center has also increased greatly in the recent years. Therefore, the energy efficiency also becomes the top priority for the equipment makers and also the data center operators.

This paper first describes the trends and the critical thermal issues in the current telecommunication industry, and then follows with the possible solutions to the issues. The thermal technology map is developed as a general guideline to select the proper cooling schemes for the 
system under consideration. The discussion is then extended to the development of liquid cooled telecommunication equipment which is a must to meet power density challenge in the future systems. General design guidelines of liquid cooling are discussed in details. Because of the rapid growth in energy consumption and its related cost, the energy efficiency of the data center becomes a major issue to be considered in the industry. This paper also presents the critical steps needed to achieve the energy efficiency at the equipment and in data center by integrating thermal management into system design.

\section{Industry trends and critical issues}

Currently, telecommunication equipment is facing numerous challenges. The major one on the system level is power density. Architects of the next-generation network core are demanding exponentially higher system throughputs to keep up with network traffic growth. With the extrapolation from current equipment, future nodes would consume and dissipate up to 100's of kilowatts of power. This trend as shown in Figure 1(2) is reflected in the projected growth in heat flux based upon footprint area at the equipment level. As can be seen from the figure, the system power for the core network is the highest among all products presented in the figure.



Figure 1 Thermal Loading at Facility Level for Various Products

Since the current telecommunication systems are still focusing at the air cooling, large high performance fans are becoming a must for the high power systems in order to provide the adequate air flow rates to the system. In addition to the system thermal issues, two major concerns about these large fans are the power consumption and the acoustic noise of the fans. The former is related to the equipment energy efficiency while the latter is strictly regulated by the government and industry standards such as NEBS in North America, and ETSI in Europe. For the acoustic noise limits, the GR-63 of NEBS states that the acoustic noise of any equipment must be less than $78 \mathrm{dBA}$ (sound power) at the ambient of $27{ }^{\circ} \mathrm{C}$. On the other hand, ETSI states that the acoustic noise (sound power) should be limited to $72 \mathrm{dBA}$ or less at the ambient of $23{ }^{\circ} \mathrm{C}$.

The increased system power results in a significant increase in the power consumption and the cost of powering and cooling of the equipment as well as the data center. Consequently, the energy efficiency becomes the top priority for the equipment manufacturers and the data center operators. The COP (coefficient of performance) is often adopted in the telecommunication industry to measure the thermal or energy efficiency of the equipment. The COP is defined as the ratio of the total system power, including power from electronics, power supply/converters, and fans to the total 
power consumption of fans or thermal control units. Therefore, the higher power consumption of the fan, the lower system COP will be. In general, the COP of any equipment at the worst case condition with fans at full speed should be greater 10 .

\section{Thermal management and roadmap}

Currently, air cooling is the main cooling method for all current telecommunications equipment with exception of a few outdoor equipments.

The overall thermal management challenges for the next generation telecommunication equipment are as follows:

1) Heat removal from high density and high heat flux packages within reduced volume at low system pressure drop.

2) Hot spot thermal management in packaging level

3) Heat spreading from chip packages (small area) to heat sinks or cold plates (large area)

4) Thermal integration with EMI for high speed, low voltage packages

5) Integration acoustic noise management into system thermal solutions

6) Precise temperature control for optical/photonic packaging

7) New interface materials with high thermal conductivity and matching CTE

8) Advanced analysis tools for thermal modeling and analysis

9) Improvement on PCB thermal performance, e.g., enhancing thermal spreading on PCB

10) Integration energy efficiency into system thermal design

The thermal issues in the chip packaging are due to the increase in chip power and the local hot spots. The primary goals of thermal management are to minimize the component junction temperatures and the temperature gradients of the chip packages. The TIM1 (thermal interface material between silicon die and lid) is the most critical factor because it controls the heat transfer from the junctions to the case.

The possible methods of reducing the $\Delta \mathrm{T}$ across the TIM1 can be described as follows:

a) Thin film thermoelectric device ( by Nextreme)

b) Indigo- 1 Phase change metallic interface with $\mathrm{K}=20-40 \mathrm{~W} / \mathrm{m}-{ }^{\circ} \mathrm{K}$ ( by Enerdyne Solution)

c) Reactive bonding of multilayered foils composed of thousands of nanoscale layers (by Reactive Nano Technologies, Inc)

d) Any materials with high thermal conductivity, e.g.,Indium with $\mathrm{K}=86 \mathrm{~W} / \mathrm{m}-{ }^{\circ} \mathrm{K}$ (by Indium Corporation)

However, except special customer made chips, users have no control over the thermal performance of the chips

Among the many system level challenges faced in telecommunication equipment manufacturers, the power density is the most critical one thermally. The power reduction strategies and highdensity thermal management become two of the critical elements for the future telecommunication equipment.

TIM2 (thermal interface material between package case and the heat sink or cold plate) control s the heat transfer from chip to the heat sink for air cooling or cold plate for liquid cooling, respectively. To achieve the efficient thermal management schemes, the following factors should be considered

1) Optimizing of heat sinks or cold plates on components for air or liquid cooling

2) Using high thermal conductivity thermal interface materials (TIMs) with matching TCE

3) Employing good air flow management with lower system pressure drop

Another critical issue to heat sink performance is the base spreading resistance of the oversize heat sinks. To reduce the thermal spreading resistance, the common methods are to increase the 
lateral heat conduction at the heat sink base. The approaches include but are not limited to the embedded graphite spreader (or any high thermal conductivity materials), embedded heat pipes, vapor chamber or liquid chamber base.

The thermal technology map for various power systems with different cooling schemes is developed and presented in Figure 2 (3). The horizontal axis shows the estimated heat transfer coefficients. The left vertical axis in the figure gives the system power while the right vertical axis represents the system complexity and cost. Generally, the cooling system becomes more complicated and costly when the system power increases. Figure 2 should only be used as a general guideline. It is believed that the upper limit of the forced air cooled rack is about 25000 watts. Liquid cooling may be considered for system power greater than this value.. For practical engineering applications, the forced air cooling is not recommended for any system over $20 \mathrm{KW}$ even it works thermally, because of acoustic noise and the COP issues.

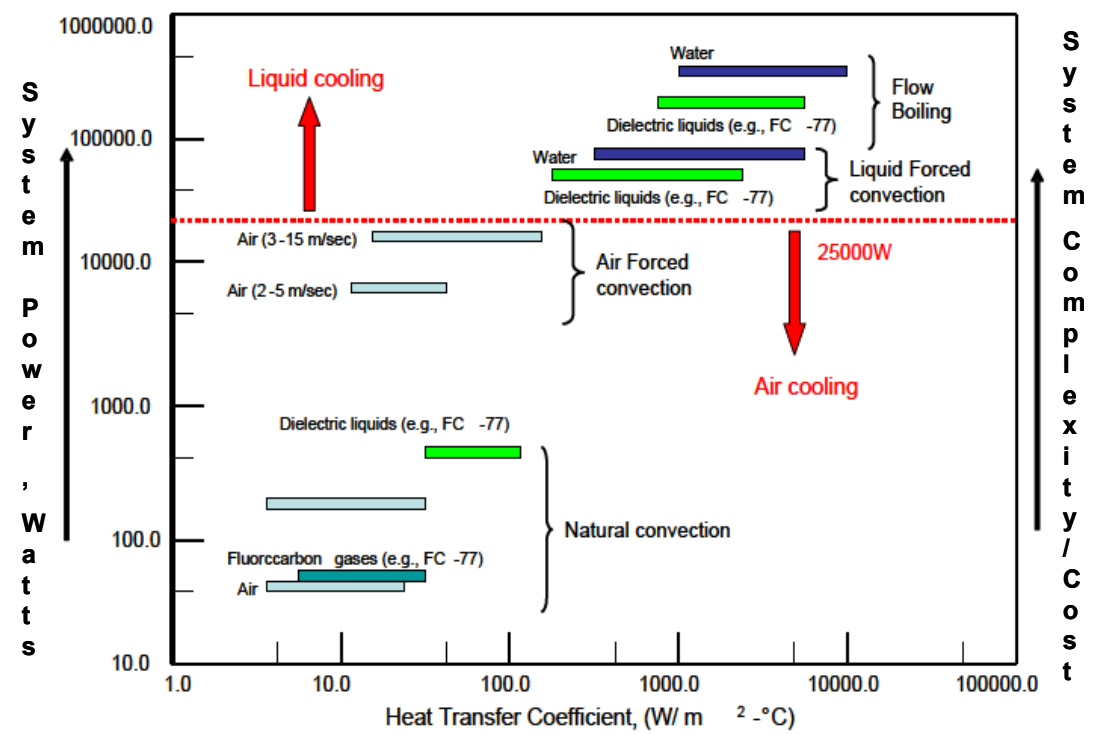

Figure 2 Thermal Technology Roadmap

The flow management is another important factor for achieving the effective thermal management scheme. The objective of the flow management is to obtain proper flow distribution over the boards and also to minimize the system flow resistance or pressure drop in order to increase the system flow. The baffles are also often employed to improve the flow distribution over the board or to guide flow to where it is needed. In addition, system design must have a good balance between the desired system thermal performance and the pressure drop.

\section{Liquid cooling}

The greatest advantage of liquid cooling over the air cooling is its cooling capability. Though, the liquid cooling has long been employed in the high performance computers, the current practice of using liquid (i.e., water) at the equipment in the data centers is aiming at the reduction of the system exit air temperature to the data centers. IBM System 360 Model 91 in 1967 was the first IBM computer to use water-cooling in any form. The water-to-air heat exchangers as shown in Figure 3 (4) are installed at the door and are inserted between the card cages when the door is closed. The purpose of the water-to-air heat exchangers is to reduce the inlet air temperature to the upper card cages (boards) in downstream of the air flow. As can be seen from the figure, the $\Delta \mathrm{T}$ air is reduced by more than $20^{\circ} \mathrm{C}$ with the heat exchangers in the rack. 
On the other hand, the IBM RDHX (rear door heat exchanger) (4) which is a water-to-air heat exchanger is attached to the exits of the computer or telecommunication rack as illustrated in Figure 4. The overall dimensions are 25 " (W) x 5.6" (D) x 76.4" (H). The main purpose of the RDHX is to lower the temperature of the exit air from the servers to the date center so that the energy consumption of the air-conditioning units in the data center can be reduced. It should be noted that the RDHX does not affect the thermal performance of the equipment itself.

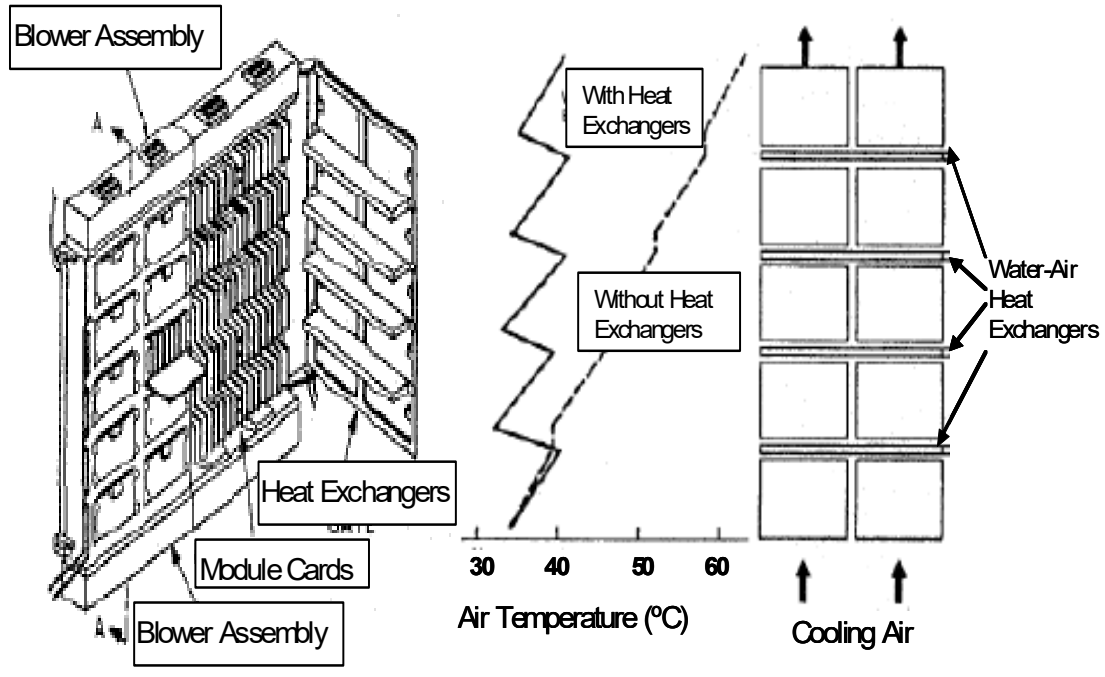

Figure 3 IBM Water-Air Heat Exchangers in Cabinets

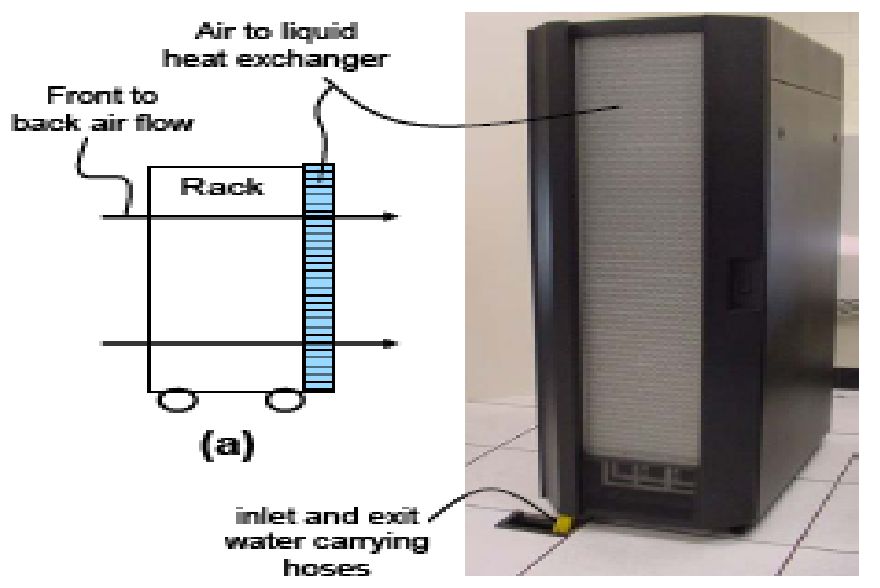

Figure 4 IBM Rear Door Heat Exchanger

There are two ways as shown in Figure 5 for liquid cooled componenst. One is to attach the external cold plate to the component case just as the heat sink to the component for air cooling. Another is to directly integrate microchannels to the silicon die. Thermally, the latter is much effective due to the much short thermal path from the heat sources to the coolant. 


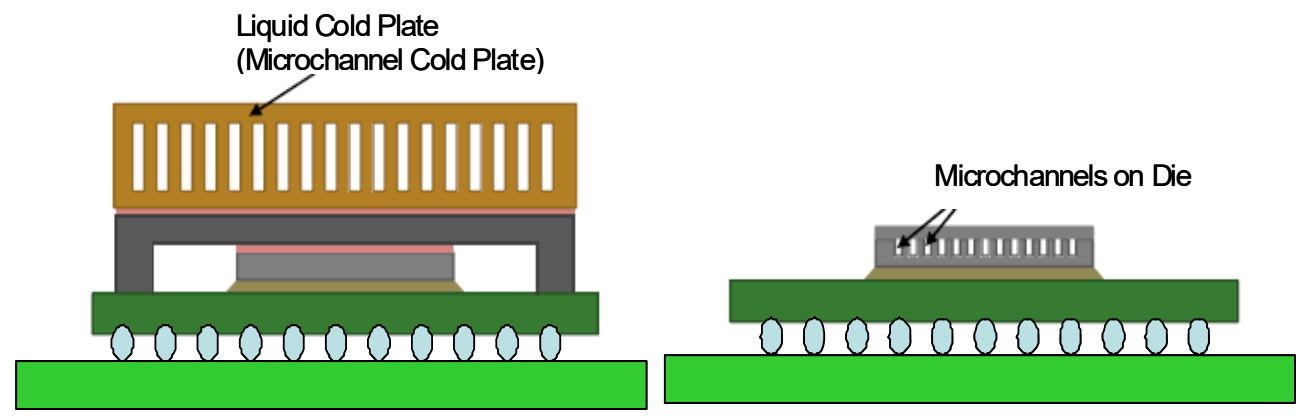

Figure 5 Liquid Cooled Components

A liquid cooling of chip package based on the microchannel technology as shown in Figure 6 was first proposed by Tuckerman $(5,6)$. The integrated microchannels are directly at the back of the silicon chip which greatly reduces the thermal path length from the heat sources to the coolant. The height and width of individual cooling channels are $300 \mu \mathrm{m}$ and $50 \mu \mathrm{m}$, respectively. The power of 790 watts is dissipated over the $1 \mathrm{~cm} \times 1 \mathrm{~cm}$ chip. The experimental results with the water flow rate of $8.6 \mathrm{ml} / \mathrm{sec}$ indicate that the temperature difference from the coolant inlet and maximum cold plate temperature is $71^{\circ} \mathrm{C}$. and calculated $\mathrm{h}=11.13 \mathrm{w} / \mathrm{cm}^{2}-{ }^{\circ} \mathrm{C}$. Thermally, the microchannel cooling is very effective but its pressure drop of $31 \mathrm{psi}(214 \mathrm{KPa})$ at the flow rate of $8.6 \mathrm{ml} / \mathrm{sec}$ is also too large to be acceptable for practical applications

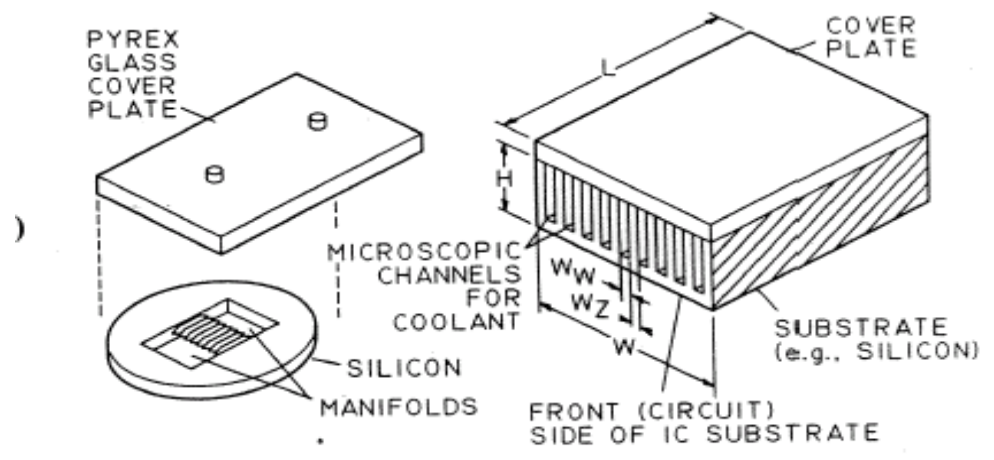

Figure 6 Microchannel Cooled Silicon Chip

Recently, the advances in manufacturing technologies, including the progress in high-rate, deep reactive ion etching of silicon have made possible for the easy fabrication of silicon microchannel cooler at the reasonable cost (7). In addition, the methods for reducing the pressure drop have also been reported, including subdividing the flow into multiple heat exchanger zones with shorter channel lengths and manifold designs with large cross sectional area is presented in Figure 7. For flow rate at $1.01 \mathrm{l} / \mathrm{min}$, the overall thermal resistance and the pressure drop are $17.5{ }^{\circ} \mathrm{C}-\mathrm{mm}^{2} / \mathrm{W}$ and $30 \mathrm{KPa}$, respectively. 


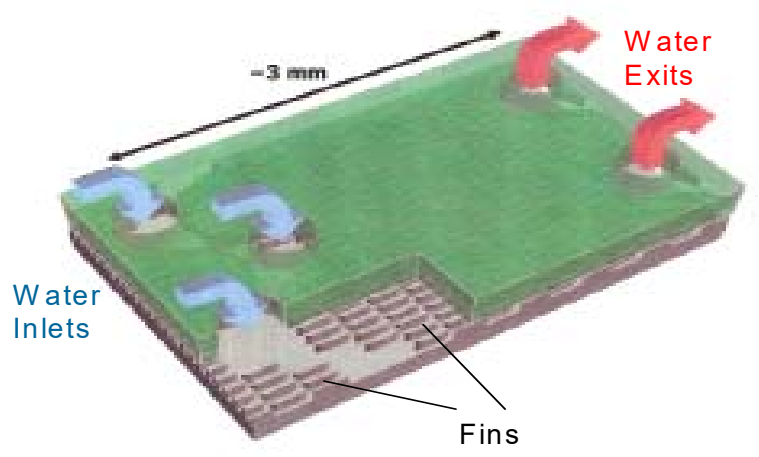

Figure 7 IBM Microchannel Cooled Silicon Chip

Due to the increased power requirement, the vertical integration of the circuit die which is also referred to as "3D Packaging" has received considerable attention in the recent years. Thermally, the vertically stack chip packages are even more demanding than the traditional $2 \mathrm{D}$ chips. The current design of 3D IC package with two layer dies is given in Figure 8. (8). The interconnection between the dies is through silicon vias. There is no difference in transferring heat from the junction to the case between the traditional $2 \mathrm{D}$ and this $3 \mathrm{D}$ flip chip packages. The heat sink or cold plate can be directly attached to the case of the component in air or liquid cooling.

The backside heat removal using the microchannel cooling technology which was first proposed by Tuckerman and Pease $(5,6)$ has been shown effective for the single layer die. The multiple interlayer integrated water cooling proposed by Reference 9 as shown in Figure 9 is a very promising approach. The major challenge in the thermal design of this $3 \mathrm{D}$ chip package is how to remove heat from interior layers of the dies. For these high power 3D chips with multiple layer dies, the traditional air or even the liquid cooling techniques are not possible because of the difficulty of heat remove from the internal layers. The only one effective method is to use multiple-layer microchannel liquid cooling on the integrated circuits as proposed in Reference 9.

The hybrid cooling of the supercomputers by IBM (4) and by Futjitsu (10) as illustrated in Figures 10 and 11, respectively has recently received considerable attention. The high power components on the board are cooled by the liquid while the rest of components are still cooled by the air. The issue of possible condensation inside the rack must carefully be considered. The possible fan failure and also the acoustic noise issue may still exist in the hybrid cooling scheme. In addition, the liquid loop (tubes) may become obstacle of the certain air flow to the components. IBM Zurich Research Lab in conjunction with ETH developed a warm water $\left(60^{\circ} \mathrm{C}\right)$ cooled supercomputer (Aquasar) using microchannel cold plate for cooling the components as shown in Figure 13 (11). 



3DIC-through silic on via in terconnect

Figure 8 2D and 3DIC Flip Chip Packages

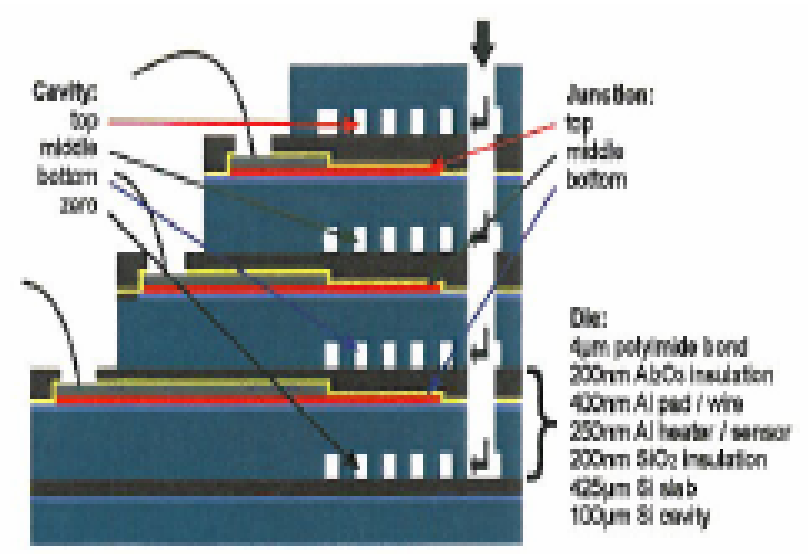

Figure 9 IBM Zurich Microchannel Liquid Cooled 3DIC

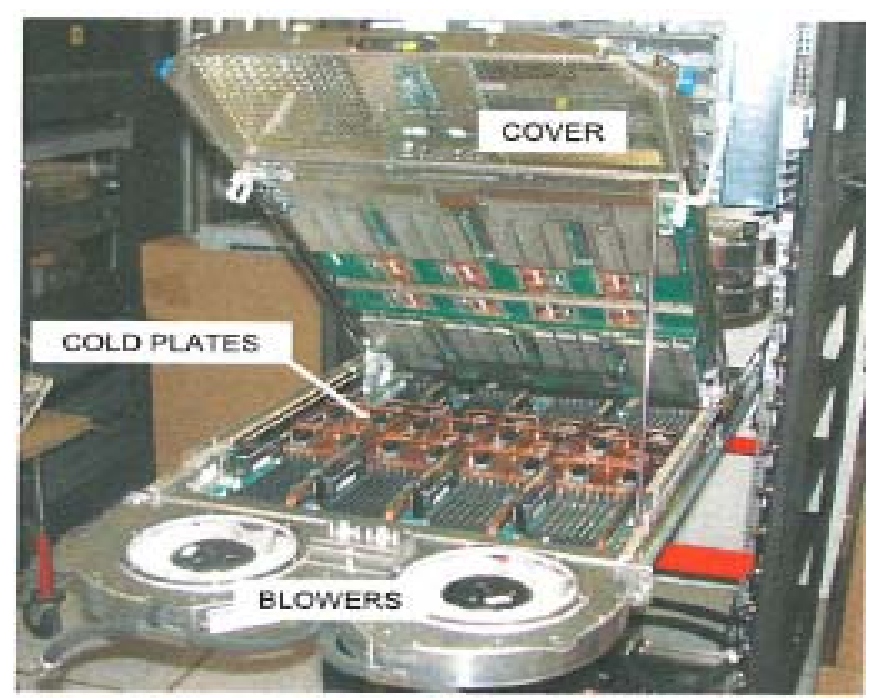

Figure 10 IBM Power 575 System 

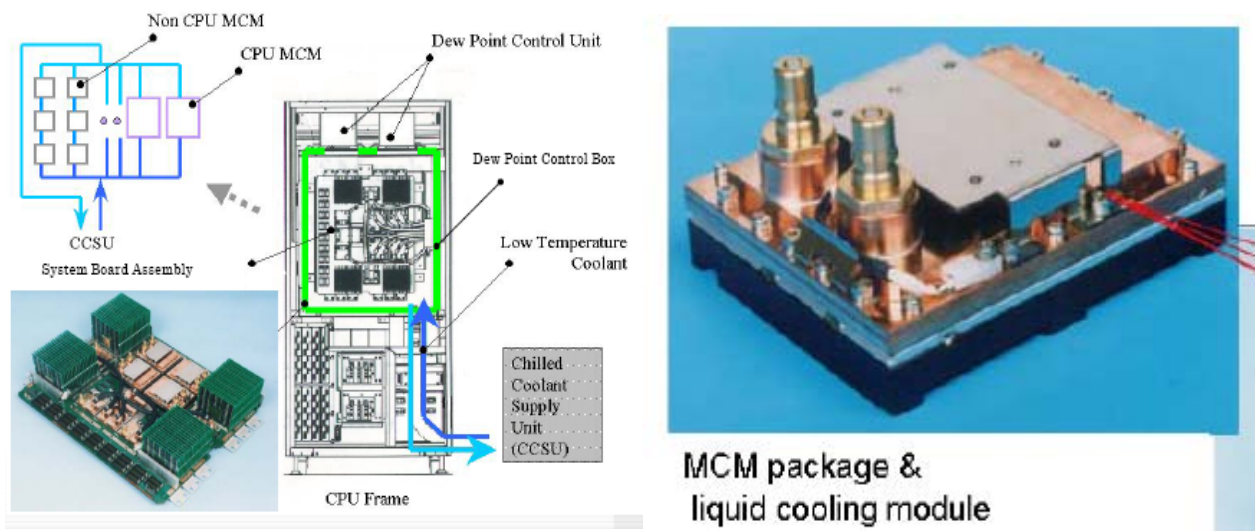

Figure 11 Fujitsu High End Server (GS8900)



Figure 12 IBM Zurich Liquid Cooled Board

The active liquid cooling (total liquid cooling) is the best approach to achieve the energy efficiency both at equipment level and data center. The actively liquid cooled rack has following advantages over the current air cooled rack.

- $\quad$ Liquid cooling can support much higher system power

- Liquid cooled rack makes equipment much more reliable

- $\quad$ By eliminating fans and air filter, equipment reliability is significantly increased

- $\quad$ Effective liquid cooling also lowers component temperatures

- $\quad$ Liquid cooled rack is much more compact and small

- $\quad$ By eliminating fan tray, air filter, air inlet and exit spaces

- $\quad$ Slot size (spacing between boards) is small so more boards can be included

- Equipment is almost maintenance free (no need to replace air filter and fans)

- $\quad$ Operation cost is also reduced by eliminating fans and air filters

- Liquid cooled rack can totally eliminate acoustic noise from fans and high speed air flow

- Liquid cooled rack is independent of ambient conditions (e.g., room air temperature) as long as chilled liquid is available

- Eliminating hot air from equipment will reduce data center temperature and decrease energy consumption in data centers

\section{Liquid cooled telecom equipment}

The liquid cooling has not been adopted commercially by any indoor telecommunication 
equipment. However, due to the increased system power and also the concern about the energy efficiency, the liquid cooling has been received considerable attention in telecommunications industry recently. Alcatel-Lucent has developed a sealed cabinet using dielectric mist for cooling as illustrated in Figure 13 (12).

The large droplets of dielectric mist from the atomizer are injected into the upstream of air flow entering the printed circuit boards. The liquid mist is heated by the electronics on the board and is evaporated along the air stream. In other words, heat generated from electronic components is used to vaporize the dielectric mist instead of heating up the air stream that reduces component temperatures. The mixture of air and the dielectric vapor flows over an array of heat pipes and the dielectric vapor is then condensed and the liquid is fallen into the liquid collector and finally is pumped into the atomizer for reuse.



Figure 13 Alcatel-Lucent Enhanced Cooling in a Sealed Cabinet

Cisco also employed the hybrid cooling for the high power system which is the modified 7609 Series (13). The back side of chassis, including the heat exchangers, tubing and the pumps is shown Figure 14. The system under consideration is a standard 19" rack which consists of 9 boards with the board pitch of 1.8 ". The maximum system power per shelf is about $10 \mathrm{KW}$ with the maximum nominal power per board of $1000 \mathrm{~W}$.

Both systems from Cisco and Alcatel-Lucent are still in the very preliminary phase in the laboratory. Some of other telecommunication equipment manufacturers have also started considering various forms of the liquid cooled systems, including two phase flow refrigeration systems. 


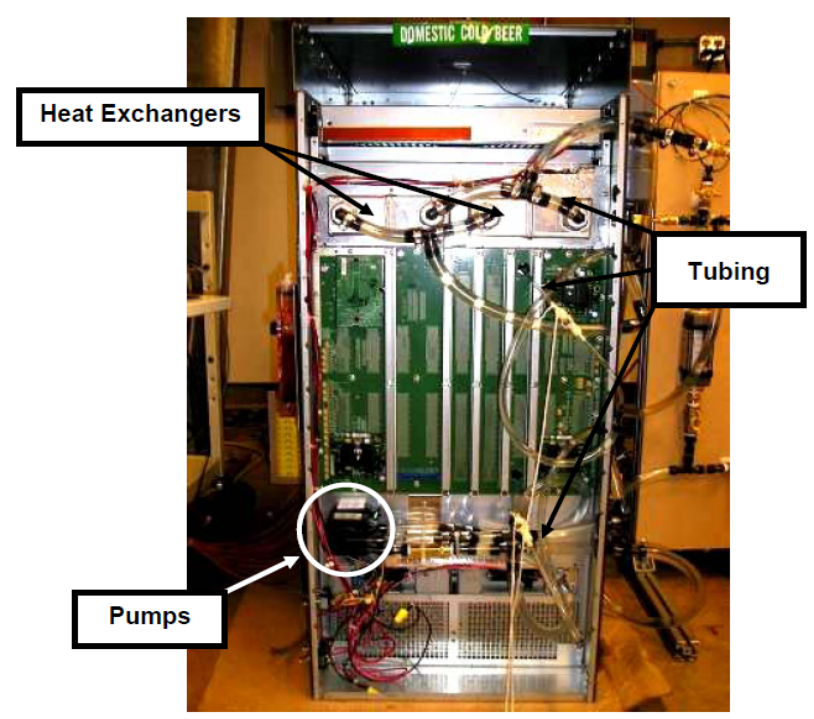

Figure 14 Cisco Liquid Cooled Rack : Back of Chassis Exposed

The chilled water is readily available in most of the data centers. The cooling concept of the active liquid cooled rack is given in Figure 15 (3). The liquid enters the inlet manifold which provides proper flow rate to the individual boards and leaves the equipment through exit manifold. The chilled water in Figure 16 is directly taken from the data center. It should be noted that the pump may not be needed in this case if water from the date center has sufficiently high pressure. The flow rate to individual boards must be regulated in proportion to the power of the boards.

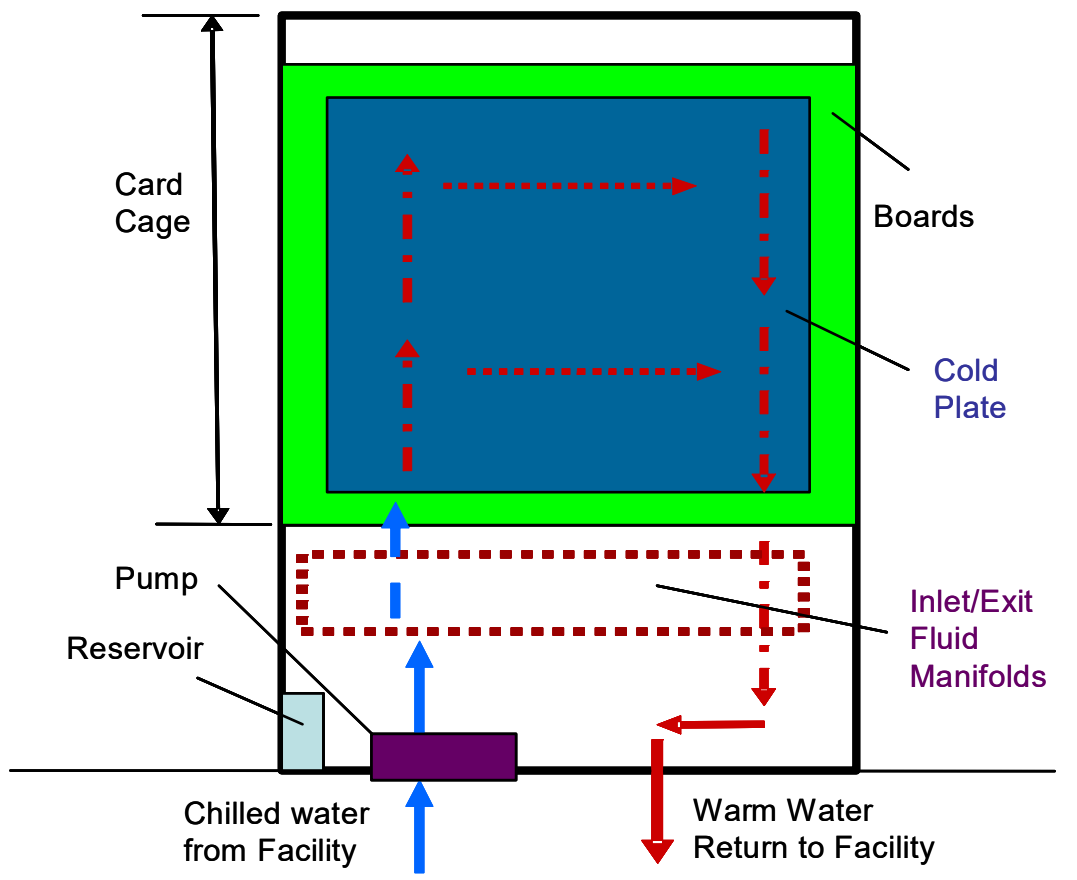

Figure 15 Active Liquid Cooled Rack with Facility Water

On the other hand, Figure 16 (3) illustrates the liquid cooled equipment with the self supplied liquids. In this case, an additional heat exchanger is required in order to cool the hot liquid from the equipment to be reused again. This heat exchanger can be a liquid-to-liquid heat exchanger or an air cooled condenser. 
Figure 15 can also be applied to the outdoor systems which dielectric liquids must be used in the outdoor applications. This is due to the fact that the outdoor equipment is typically required to operate at the temperature below $-40^{\circ} \mathrm{C}$ or even $-50^{\circ} \mathrm{C}$. In general, a dielectric liquid which has a high dielectric strength to prevent electrical breakdown is a preferred choice in cooling of electronics. Unfortunately, the heat transfer capability of the dielectric fluids is much lower than that of the water. The dielectric liquid is not normally required for the cases with indirect liquid cooling. However, it is a must for the direct immersion cooling where liquid is in direct contact with electronics.

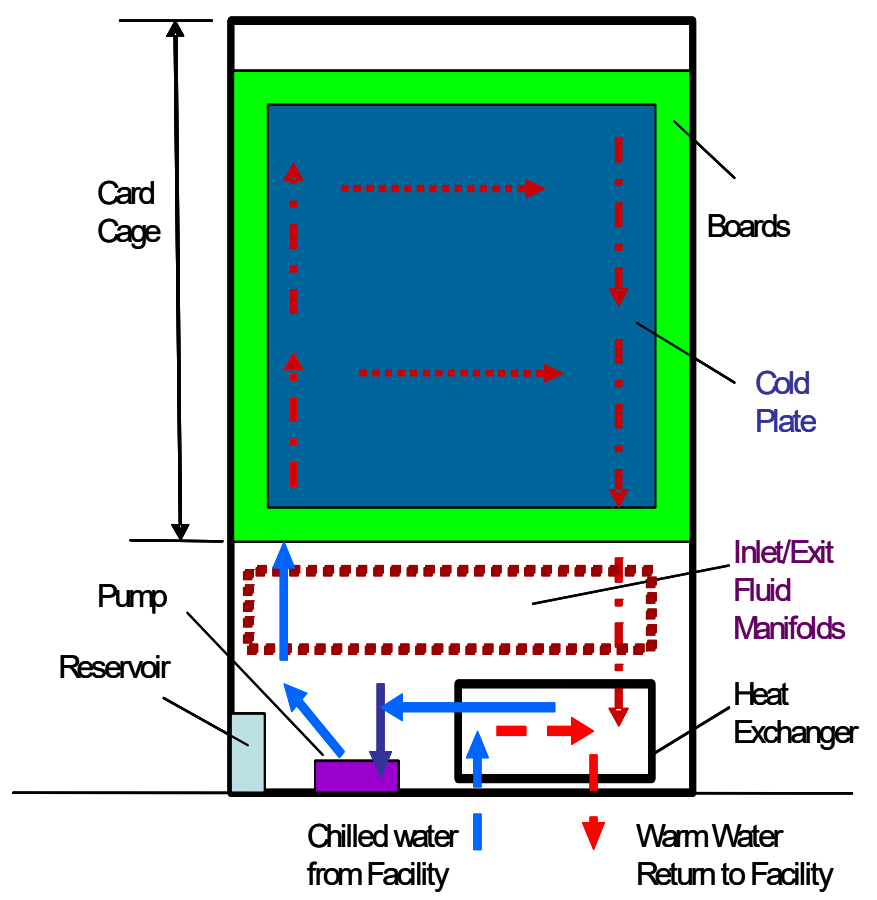

Figure 16 Active Liquid Cooled Rack with Self Supplied Coolant

Figures 15 and 16 illustrate general liquid cooling schemes for the liquid cooled telecommunication equipment. However, for the real systems, the board assembly, including board and its cold plate must be able freely connecting or disconnecting into the equipment. To do so, each board requires at least 2 quick disconnects for the liquid loop. Quick disconnect are needed to avoid any liquid leakage after the board assembly is unplugged from the system. Yeh (3) propose an active liquid cooled telecommunication system as shown in Figure 17 (3) which illustrates the connection of the board assembly to the system. It should be noted while the board is plugged into the back plane for the electrical connection meanwhile the liquid loop must be connected to the system too. The figure which shows one cold plate for all components on the board is just for illustration purpose only. Due to various heights of the components on the board, multiple cold plates may be required. 

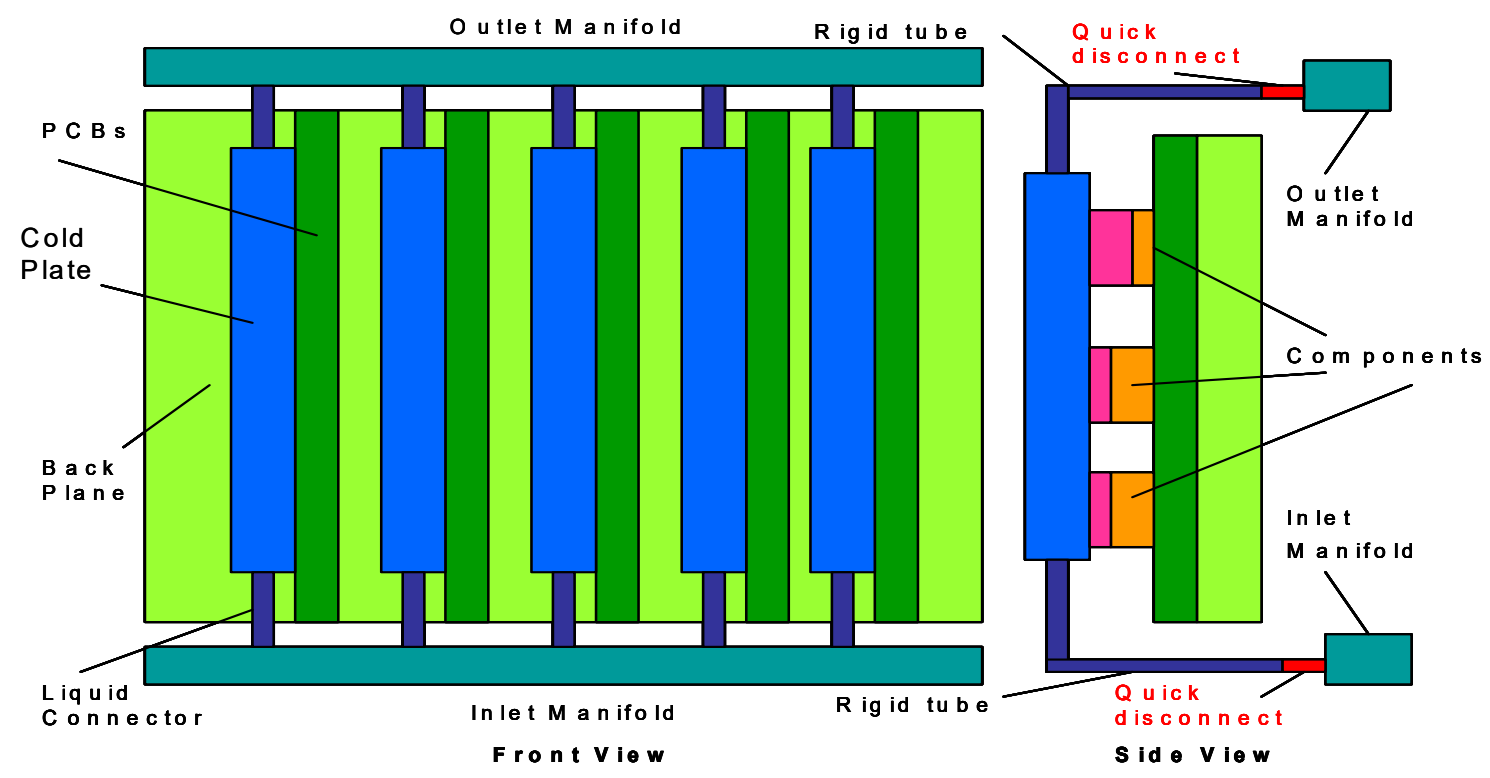

Figure 17 Sketch of Board Assembly Connection to System

All liquid cooling schemes discussed above can also directly be applied to the two phase flow systems which include the boiling heat transfer. The advantages of two phase flow over the single phase liquid flow systems can briefly be summarized as follows:

- Extremely high heat transfer capability

- Utilization of latent heat (heat of vaporization)

- Uniform temperature distribution over devices (heat sources)

- $\quad$ Phase change occurring at constant temperature for a given system pressure

- $\quad$ Keeping device at constant temperature with varying heat load (device power)

- $\quad$ Maintaining near same temperature for multiple devices/heat sources

- Compact and light weight systems

- Quick thermal response

- Low acoustic noise

\section{General liquid cooling design guidelines}

Selection of a coolant for a liquid cooled system is a very important design consideration, especially for new systems. The first step is to establish the important system characteristics, such as weight/volume limitation, power consumption requirement, and leak-tightness. In general, a fluid may be very good in some respects and quite deficient in others. Therefore, there is no single, ideal fluid that is good for all systems and applications. Consequently, various fluid properties of the coolants should be evaluated against the particular systems and applications under consideration. In addition, coolants must be chemically compatible with the materials, which they will contact within the coolant loop, and from leakage. References 14 and 15 provide an excellent review of this subject.

Water is the most common fluid used in cooling the high power computers because of its high heat transfer capability. However, water can not be used in a direct immersion cooling or for outdoor applications. The former is due to its poor dielectric properties and the later is because of its high freezing temperature. When water is used, it also must be properly treated for anti-corrosive and -fungal. For material compatibility, copper or stainless steel must be used for the entire liquid loop if water is adopted as the coolant. On the other hand, aluminum can be employed for the 
dielectric fluids. However, stainless steel is recommended if de-ionized water is the coolant. All above three types of materials (copper, aluminum, and stainless steel) are compatible with Glycois.

The parallel flow paths should be employed in the system or over the board. The major advantage of the parallel flow over the series flow system is to provide minimum pressure drop and maximum distribution of the cold liquid. The system pressure drop is extremely small for the parallel flow arrangement as compared to the series flow system because of small flow rate (fraction of the total flow) and short flow length of each parallel flow path. In addition, the temperature difference among all boards is relatively small. On the other hand, the fluid is continuously heated in the series flow arrangement which results in a large the temperature difference between the inlet and exit. It should also be noted that the pressure drop through each of the parallel path is essentially the same.

In order to provide sufficient coolant to each flow path, the flow rate to each path (boards) must be proportional to the heat load of individual paths (boards). However, a large flow rate will still be needed even for a low power board if this board includes critical components such as optical modules with low component temperature limits or the board has extremely high power components. Therefore, the flow rate to individual paths must be properly regulated.

In addition, the equipment must also be designed with redundant cooling loops to insure the system reliability though it makes system more complicated and costly. One of examples is that the system has two independent and separate flow paths through the entire cold plate.

Generally, the effects of coolant properties on heat transfer and friction factor is minimum because of small to moderate temperature difference between the inlet and exit of a cold plat. However, it may become critical issue in the microchannel cooling systems because very small flow rate in such systems may result in large temperature gradient over the cold plate. The heat transfer in microchannels is very effective but it also has a large pressure drop because of extremely small cooling channels. Due to high pressure drop, the liquid coolant could boil near or at the exit of the cooling systems.

Two phase flow cooling has much higher heat transfer capability than that of single phase liquid cooling. However, the two phase flow system is much more complicated which requires the vapor be condensed for reuse. For liquid cooled systems, including all current supercomputers, water must be boiled at around $60{ }^{\circ} \mathrm{C}$ or lower in order to maintain the chip junction temperature below $85{ }^{\circ} \mathrm{C}$. The boiling point of water at atmospheric pressure $(14.696 \mathrm{psia})$ is $100{ }^{\circ} \mathrm{C}$. Therefore, water to boil at $60^{\circ} \mathrm{C}$, the system pressure must be adjusted to about 2.9 psia by pulling the vacuum. On the other hand, the boiling point for FC-72 at the atmospheric pressure is at about $60{ }^{\circ} \mathrm{C}$. For refrigeration fluids and Ammonia, very high pressure is required to achieve $60^{\circ} \mathrm{C}$ boiling point.

For any forced convection system, the pressure drop is as important as the heat transfer. A high pressure drop system will require a large pump which not only consumes more power but also is heavy and costly. High heat transfer always accompanies by the high pressure drop. A good system design must have a good balance between the heat transfer and the pressure drop. Therefore, the goal of system thermal design is to maximize heat transfer and to minimize pressure drop. The best way to achieve the goal is to adopt efficient cooling schemes which will require the least flow rate.

\section{Energy efficiency}

As stated previously, the equipment power consumption is continuously increased at a fast pace. Furthermore, the worldwide electricity usage of data centers has increased from 71 billion $\mathrm{kWh}$ per year $(0.5 \%$ of the worldwide total electricity usage in all sectors) in 2000 to $152 \mathrm{kWh}$ per year ( $1 \%$ of the worldwide total electricity usage in all sectors) in 2005 (10). Figure 18 (16) illustrates the power consumption in a typical data center. Among them, the power consumption for the IT and 
cooling equipment are about $50 \%$ and $33 \%$, respectively. In addition, the cost of powering and cooling in the equipment at the data centers has also increased significantly and the energy cost becomes the fastest growing expenditure in the date centers. Therefore, the energy efficiency at the equipment level and the data center become a top priority in the industry.

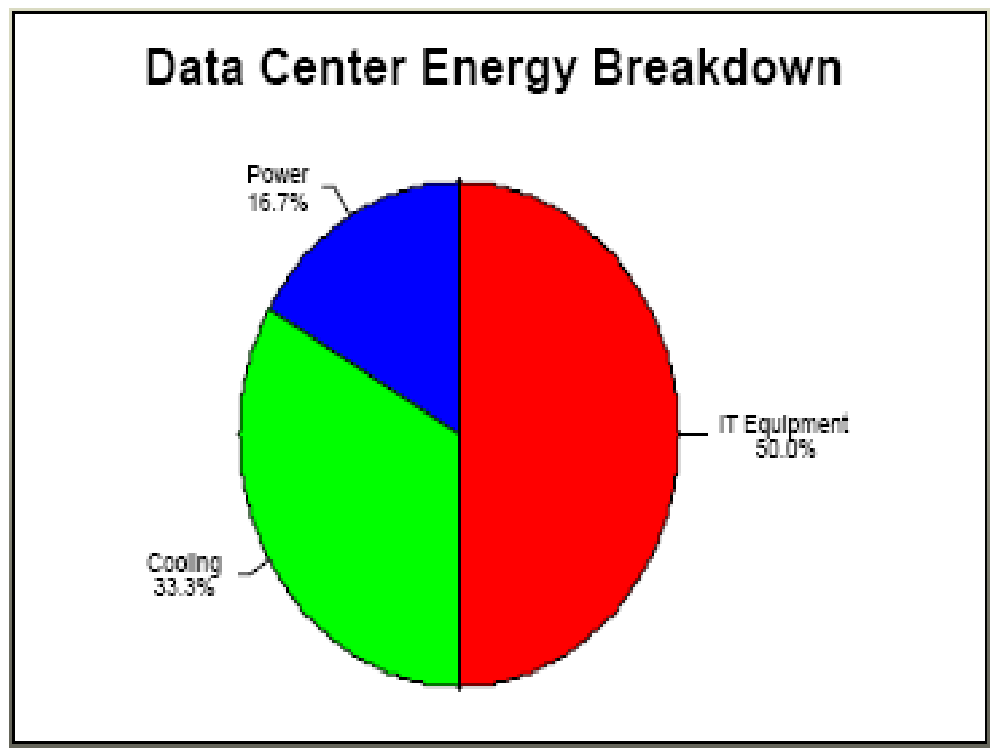

Figure 18 Typical Data Center Energy Breakdown

Because of the rapid growth in energy consumption and its related cost, the energy efficiency of the data center becomes a major issue in the industry. The most common factor used to measure the energy efficiency of the data center is the power utilization effectiveness (PUE). PUE represents the ratio of total power required to operate the data center, including powering and cooling, power and other overheads to the power of used by IT equipment alone. The values of PUE depend on the cooling system architecture. For example, typical PUE is about 2.7,for a traditional raised floor data center and is $1.7-2.1$ by applying additional in-row cooling and a better containment of hot and cold air. The PUE can further be reduced to about 1.3 by using advanced containment methods such as rear door heat exchangers.

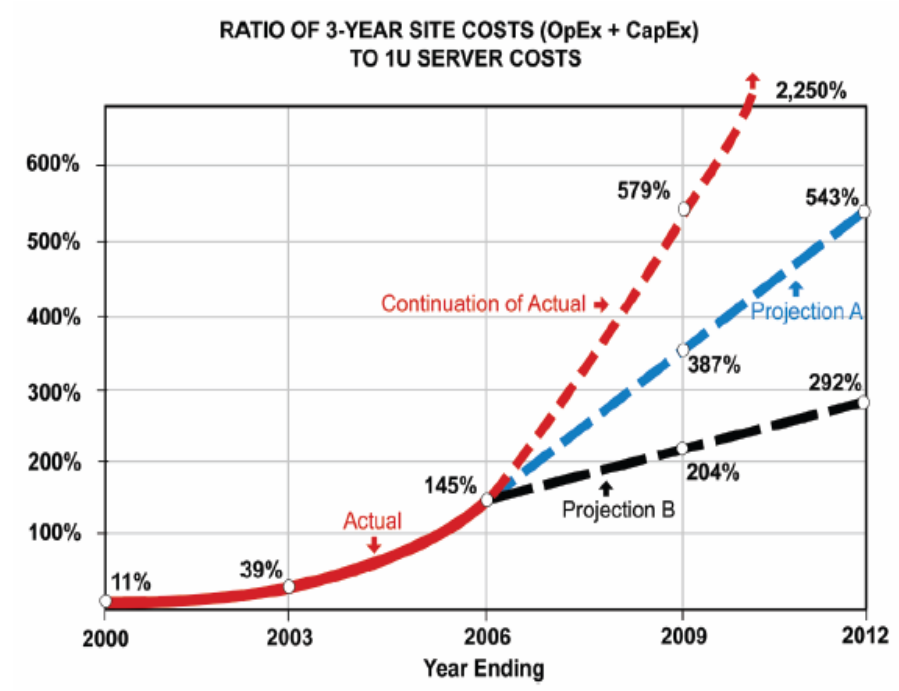

Figure 19 Ratio of 3-Year Site Cost to 1U Server Costs 
Due to significant increase in the cost of powering and cooling of the system, the total cost of system operation may exceed the cost of the equipment in a relatively short period. For example, the ratio of the 3 year site cost (total cost of operation) to the $1 \mathrm{U}$ server cost is given in Figure 19 (17). As can be seen from the figure, the 3 -year cost of powering and cooling servers is about 1.5 times of the cost of the servers in 2006 and this factor is projected to be over 22 times at the worst case by 2012 .

In addition, the power consumption of equipment has a great impact on the power required in a data center which is directly related to the operation cost. Based on the estimate by Verizon (18), one watt saved at the equipment level will save a total of 2.41 watts in their respective the data center as shown in Figure 20. Therefore, it is extremely important for the equipment makers to do a better job on energy efficiency of their products. It should be noted that this cascade factor varies slightly with the individual data centers.

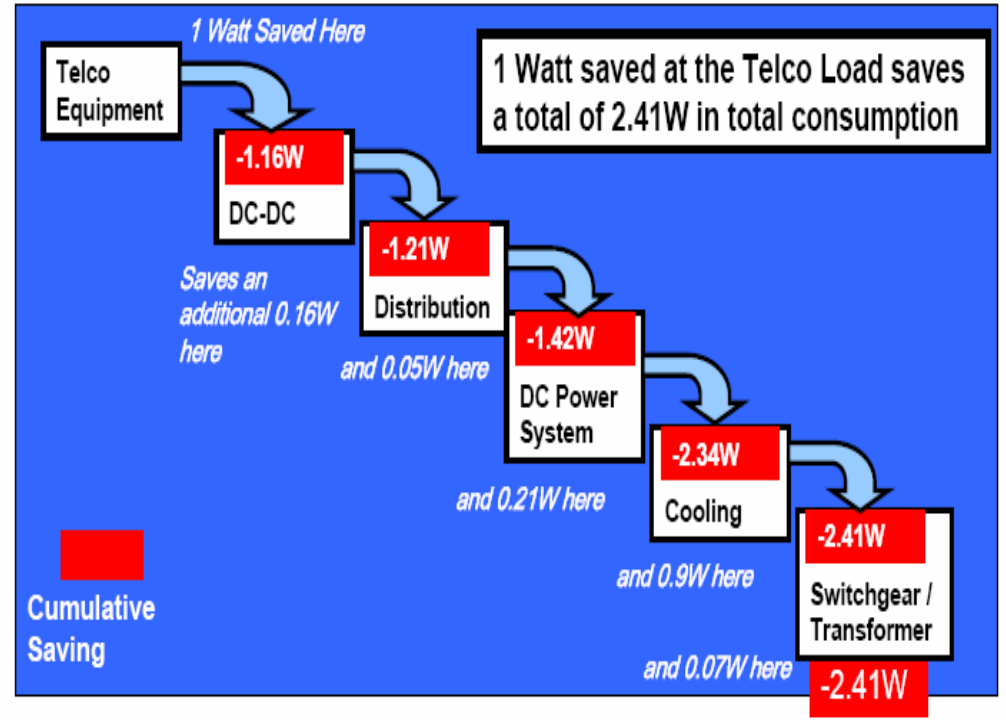

Figure 20 Cascade Effect of Energy Savings from Equipment to Data Center level.

The following steps (3) may be considered to achieve the energy efficiency at the equipment

1) Using low power consumption components, especially for power supply.

2) Utilizing industry grade components whenever possible

The industry grade parts are more expensive but are more reliable. In addition, the industry grade component can withstand higher temperature that in turn requires less air flow

3) Employing efficient thermal control schemes

The fans can operate at low speeds because the less flow is required with effective heat transfer methods

4) Designing equipment with power management features

With this feature, some of boards can shift to standby mode in the conditions of low traffics or demands

5) Adopting passive cooling methods whenever possible

The passive cooling is simple, reliable, cost effective and energy efficient but is limited to the low power systems due to poor thermal properties of air

6) Adopting liquid cooling, especially the actively liquid cooled equipment.

In addition, one should minimize the total power per network throughput by transferring bits in 
the optical domain from the network architectural point of view. This so-called all-optical network is a less power hungry network.

\section{Alternative energy}

With significant increase in the energy consumption and cost in the past few years, it becomes necessary to explore various types of alternative energies to supplement or even to replace the energy consumptions in the equipment and the data centers. Among them, the thermoelectric power generation and the fuel cell technology power generation have been received considerable attention recently.

\section{- Thermoelectric Power Generations}

Two major classes of application of thermoelectric devices are heat pumps and power generators. In the former, electrical energy is supplied to transport thermal energy from one location to other locations while in the latter, thermal energy is converted into electrical energy. Generally, the higher temperature difference between the hot and cold sides, the higher thermal efficiency will be. The thermal efficiency is limited by the material development. Two critical factors that dictate power output of a thermoelectric power generator are

1) The amount of heat flux that can be successfully transferred through the module, and

2) The temperature difference between the hot and cold side

Because of extremely large energy usage involved, it is of great interest in the power generation from waste heat from the telecommunication equipment and especially at the date center,. Due to relatively small air temperature difference, typically less than $20^{\circ} \mathrm{C}$, between the inlet and exit of telecommunication equipment, the thermal efficiency of the thermoelectric power generator is relatively small. The thermal efficiency with $\Delta \mathrm{T}$ of $20^{\circ} \mathrm{C}$ is currently estimated to be less than $10 \%$

Figure 21 (19) shows one of possible schemes that employ the thermoelectric power generators to convert the waste heat from equipment at data center to the electricity. Even with very small thermal efficiency, it is still worthy to try to utilize the waste heat from telecom or computing systems for the energy generation in the data center because an extremely high amount of heat is generated

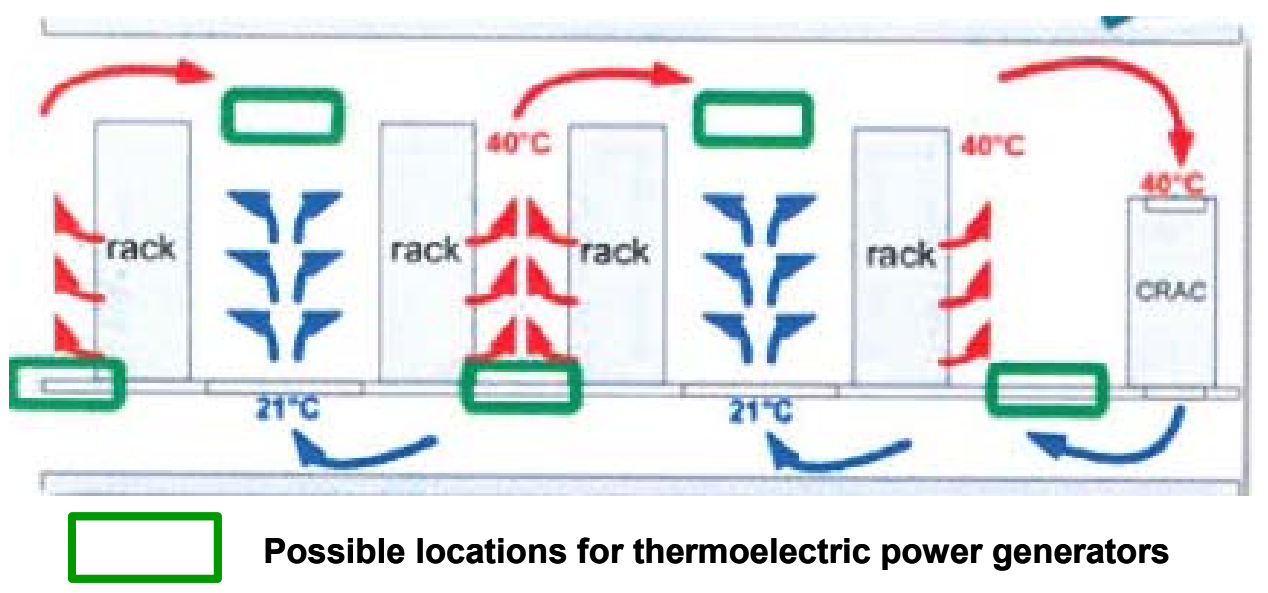

Figure 21 Possible Locations of Thermoelectric Power Generators in Data Center

\section{- Fuel Cell Technology Power Generations}

The fuel cell is an electrochemical conversion device which produces electricity from fuel (on the anode side) and an oxidant (on the cathode side) which react in the presence of an electrolyte. The reactants flow into the cell and the reaction products flow out of it.

The basic principal of the fuel cell technology is as follows 


$$
\mathrm{H}_{2}+0.5 \mathrm{O}_{2} \longrightarrow \text { Electricity }+ \text { Heat }+ \text { Water }
$$

Due to electrochemical actions, the hydrogen fuel and oxygen produce electricity and heat with the by product of water. The hydrogen is the primary fuel source for the fuel cell. The process of fuel reforming allows for the extraction of hydrogen from many sources such as natural gas and propane or any other hydrogen-containing fuels. A typical fuel cell can produce a voltage up to $1 \mathrm{~V}$ at the full rated load. Therefore, in order to deliver the desired amount of energy, the fuel cells can be combined in series or in parallel circuits, where series yield higher voltage and parallel allows a stronger current to be drawn. Such a design by combining individual fuel cells is called a fuel cell stack. To produce electrical power for a working application requires more than just one fuel cell stack. A fuel cell system may include fuel cell processing, thermal management, water management, power conditioning, electric grid connection and energy storage modules.

Fuel cell systems offer the potential for clean, reliable energy generation and have been employed to supplement the energy consumption in the data centers. Fuel cells have recently been adopted as the backup energy to or even to replace the batteries in the outside plants (OSPs). Plug Power's (20) developed GeneCore 5KW products to be used as an emergency backup power over 72 hours or more for the cell tower customers. In addition, OSP with fuel cell technology is currently available (by Commscope) in the Europe market.

\section{Summary and conclusion}

With increasing power on both component and system levels plus the demands of the reliability and performance, the thermal management becomes even more critical in the design of telecommunication equipment. The high air flow rates needed due to increased system power requires the large high performance fans which not only consume more power but also increase acoustic noise. Power reduction strategies and high power thermal management become two of the critical elements for design of the future telecommunication equipment. While larger high performance fans may generate enough air flow to adequately cool the high power equipment, however, the air cooling is not recommended for any system over $20 \mathrm{KW}$. This is because of the concerns about the fan power consumption and the excessive acoustic noise.

The operation cost of the data centers is skyrocketed in the recent years and it is also expected to be even higher in the future. The energy efficiency becomes the top priority for the data center operators and the equipment manufacturers. The methods to achieve the energy efficiency on the equipment have been discussed in the previous sections. Among them, the active liquid cooling is most attractive. The active liquid cooling not only can support even higher system power but also can eliminate the acoustic noise. And above all, the active liquid cooled rack is not only reliable but also energy efficient by eliminating all fans and the air filter which are required in the case of air cooling. It is believed that the active liquid cooling will be the choice of the future thermal management for the core telecommunication equipment.

As discussed in previous sections, one watt saved at the equipment will lead to a saving of more than 2.41 watts in the data center. This clearly demonstrates that the energy efficiency at the system level has a great impact on the energy consumption and operation cost of the data center. With the cost of energy continuous increase, the energy efficiency becomes a must for the equipment manufacturers and the data center operators. Therefore, the energy efficiency should always be integrated into the system thermal designs both at the equipment level and the data center.

Due to high energy cost, alternative energies should also be considered as the supplemental energy to reduce the operation cost of the equipment and the data centers. The thermoelectric power generation and the fuel cell technology appear to be most attractive. The latter has been employed to 
power the data centers and offices. Both of them provide clean energy with little or no pollution.

The recent papers published by Garimella et. al. $(21,22)$ presented a detailed discuss about the thermal management and energy efficiency challenges in telecommunication systems and data centers. Though the papers are mainly focusing at the high level discussions on the importance of the energy efficiency of telecommunication equipment and data centers, however, it does include a vast of data and information useful to the thermal engineers in these areas. In addition, the newly published book by Yeh and Chu (23) may be the only book totally devoted to the thermal management of telecommunication equipment. This book covers all types of telecommunication equipment, including indoor and outdoor systems and with the equipment size varying from large racks ( $7 \mathrm{ft}$ tall) to small boxes (1.75 in tall).

\section{References}

[1] Vukovic, A, "Power Density Challenges of Next Generation Telecommunication Networks", ElectronicsCooling, Vol. 9, No. 1, February, 2003

[2] Kenneth G Brill, “2000-2010 Product Heat Density Trends Chart”, White Paper, The Uptime Institute, 2006

[3] Yeh, L.T.,"Thermal Management and Energy Efficiency of Telecommunication Equipment", "Workshop on Thermal Management in Telecommunication Systems and Data Centers, Santa Clara, CA, April 25-26, 2012

[4] Ellsworth, M.J., Jr., Campbell, L.A., Simons, R.E., Iyengar, M.K., Schmidt, R.R., Chu, R.C.,The Evolution of Water Cooling for IBM Large Server Systems : Back to Future:, Itherm, 2008

[5] Tuckerman, D. B and Pease, F.F., "High Performance Heat Sinking for VLSI", IEEE Electron Devices Letter, EDL-2, 1981

[6] Tuckerman, D. B., Heat Transfer Microstructures for Integrated Circuits", Doctoral Thesis, Stanford University, 1984 Colgan, E.V, Bezama, R.J.,

[7] Gaynes, M., and Marston, K.C., “A Practical Implementation of Silicon Microchannel Coolers”, Electronics Cooling, Volume 13, Number 4, 2007

[8] Lee. Tom, "Simulation, Characterization and Interconnect, Manufacturing Technologies in electronics Packaging Thermal Design,", "Workshop on Thermal Management in Telecommunication Systems and Data Centers, Santa Clara, CA, April 25-26, 2012

[9] Alfieri, F., Tiwari, M. K., Zinovik, I., Poulikakos, D., Brunschwiler, T., and Michel, B., "3D Integrated Water Cooling of A Composite Multilayer Stack of Chips"., Proceedings of $14^{\text {th }}$ International Heat Transfer Conference, Washington, DC., USA, August 8-13, 2010.

[10]Jei Wei, "Hybrid Cooling for Fujitsu Large Computer Systems", 2010 IEEE SPJW, Kyoto, Japan, 2010

[11]Wrunschwiler, T., Meijer, G. I., Paredes, S., Escher, W., and Michel, B., "Direct Waste Heat Utilization from Liquid-Cooled Supercomputer", Proceedings of the $14^{\text {th }}$ International Heat Transfer Conference, Washington, DC, August 8-13, 2010

[12] Bahadur, V., Hodes, M., Lyons, A., Krishnan, S., and Garimella, S.V., "Enhanced Cooling in a Sealed Cabinet using an Evaporating-Condensing Dielectric Mist", Proceedings of ITHERM, Orlando, FL., 2008

[13]Glover, G., "The Next Generation Router System Cooling", MS Thesis, California Polytechnic State University, 2009

[14]Knight, A.F., "Choice of Fluids for Cooling Electronic Equipment," Electro-Technology, June, 1963.

[15]Kelly, D.J., "Resistance of Materials to Hydraulic Fluids,” Machine Design, January, 21, 1972.

[16]Schmidt,R. R., “Thermal Management Applied to Data Centers with focus on Energy Efficiency, workshop on Thermal Management in Telecommunication Systems and Data Centers, Richardson, TX, October 25-26, 2010

[17]Brill, K. G., "Data Center Energy Efficiency and Productivity", White Paper, The Uptime Institute, 2007 
[18]Graff, C., "Verizon's Thermal Management Program for Network Equipment Design”, 2009

[19]Fisher, T, "Waste Heat Recovery from Electronics", CTRC Project review meeting, Purdue University, 2010

[20]Parsons, M.J., and Josefik, N.M., "Accelerating Production Readiness using Lean Product Development", Proceedings of ASME $20097^{\text {th }}$ International Fuel Cell Science, Engineering and Technology Conference, Newport Beach, CA, June 8-10, 2009

[21]Garimella, S. V., Yeh, L. T., and Persoons, T., "Thermal Management Challenges in Telecommunication Systems and Data Centers", IEEE Transactions on Components, Packaging and Manufacturing Technology, Vol. 2, No. 8,2012

[22] Garimella, S. V., Persoons, T., Weibe, J, and Yeh, L. T., "Technological Drivers in Data Center and Telecom Systems : Multiscale Thermal, Electrical, and Energy Mangement”, Applied Energy, Vol. 107, July 2013

[23]Yeh, L.T. and Chu, R. C., Thermal Management of Telecommunications Equipment, ASME Press, 2013

[24]Yeh, L.T. and Chu, R. C., Thermal Management of Microelectronic Equipment, ASME Press, 2002 